\title{
The Thesis of Norm Transformation in the Theory of Mass Atrocity
}

\author{
Paul Morrow \\ University of Virginia - Main Campus
}

Follow this and additional works at: https://digitalcommons.usf.edu/gsp

\section{Recommended Citation}

Morrow, Paul (2015) "The Thesis of Norm Transformation in the Theory of Mass Atrocity," Genocide Studies and Prevention: An International Journal: Vol. 9: Iss. 1: 66-82.

DOI:

http://dx.doi.org/10.5038/1911-9933.9.1.1303

Available at: https://digitalcommons.usf.edu/gsp/vol9/iss1/8

This Articles is brought to you for free and open access by the Open Access Journals at Digital Commons @ University of South Florida. It has been accepted for inclusion in Genocide Studies and Prevention: An International Journal by an authorized editor of Digital Commons @ University of South Florida. For more information, please contact digitalcommons@usf.edu. 


\section{The Thesis of Norm Transformation in the Theory of Mass Atrocity}

\section{Acknowledgements}

Acknowledgments: This paper incorporates research conducted while the author was a Raab Foundation Visiting Fellow at the Mandel Center for Advanced Holocaust Studies at the United States Holocaust Memorial Museum. The paper has benefited from comments offered by Istvan Pal Adam, as well as by two anonymous reviewers. 


\title{
The Thesis of Norm Transformation in the Theory of Mass Atrocity
}

\author{
Paul Morrow \\ University of Virginia \\ Charlottesville, VA, USA
}

\begin{abstract}
Theoretical accounts of genocide and mass atrocity commonly embrace the thesis of norm transformation. This thesis holds, first, that individual and institutional participation in such crimes is at least partially explained by transformations in basic norms that structure social and political life. It holds, second, that preventing future occurrences of such crimes requires changing norms that currently guide the actions of particular individual and institutional actors. This paper clarifies, defends, and extends the thesis of norm transformation. It clarifies this thesis by providing a general account of the nature and dynamics of norms. It defends this thesis against charges of circularity and against the claim that norms are not, in fact, fundamental guides to action. Finally, it extends this thesis by arguing that changes in norms before, during, and after mass atrocities count among the considerations that ought to be included in assessments of legal and moral accountability for such crimes.
\end{abstract}

Keywords: norm inversion, mass atrocity, genocide prevention, legal accountability, moral accountability, extremely violent societies

Theoretical accounts of genocide and mass atrocity commonly embrace some version of the thesis of norm transformation. This thesis holds, first, that individual and institutional participation in such crimes is at least partially explained by transformations in basic norms that structure social and political life. It holds, second, that preventing future occurrences of such crimes requires changing norms that currently guide the actions of particular individual and institutional actors. Taken together, these two claims put the thesis of norm transformation at the center of ongoing efforts to explain and prevent genocide and mass atrocity.

Despite widespread acceptance of the thesis of norm transformation, there is no scholarly consensus concerning the nature or dynamics of norms. Political scientists and historians, sociologists and legal scholars all operate with distinct conceptions of norms, rarely considering whether those conceptions meet the needs of researchers approaching genocide and mass atrocity from alternative disciplinary perspectives. This conceptual variation has impeded critical reflection on the thesis of norm transformation, and has allowed important challenges to this thesis to go unaddressed.

This paper clarifies, defends, and extends the thesis of norm transformation. It clarifies this thesis by offering a general account of norms and norm dynamics, and by showing how this account can enrich existing explanatory and preventive applications of the thesis of norm transformation. It defends this thesis against a number of theoretical and practical challenges-including challenges to the power of this thesis to help explain historical mass atrocities, and challenges to the efficacy of proposed preventive changes in norms. Finally, it extends this thesis by arguing for a third, evaluative claim, namely, that changes in norms before, during, and after mass atrocities count among the considerations that ought to be included in assessments of legal and moral accountability for such crimes.

In proposing this extension of the thesis of norm transformation, this paper posits a fundamental continuity between explanatory, preventive, and evaluative applications of this thesis. The paper thus breaks with much recent scholarship on genocide and mass atrocity, within which these different aims appear either unrelated or at odds. ${ }^{1}$ At the same time, the paper acknowledges key criticisms of existing modes of assessing legal accountability for mass violence. Those criticisms help structure the discussion of the evaluative implications of the thesis of norm transformation.

The paper proceeds as follows. Section One uses a case drawn from the annals of National Socialist medical practice as the starting point for a general discussion of norms and norm dynamics. Norms are defined in terms of three features: their acceptance, their particularity, and their action- 
guiding power. Different types of norm transformations are then distinguished, including norm inversion, norm breakdown, and norm emergence.

Section Two examines in more detail existing explanatory and preventive applications of the thesis of norm transformation. Applications of both types, it is argued, rely on three basic theoretical assumptions. The first assumption is that it is possible to reliably identify differences in the norms accepted by particularly situated individuals across two or more moments in time. The second assumption is that norms have a fundamental, or non-reducible, power to guide the actions of individuals and thereby pattern the conduct of groups. The third assumption is that it is possible to pinpoint specific mechanisms by which particular changes in norms have been, or might be, achieved.

Section Three addresses two significant challenges to current explanatory and preventive applications of the thesis of norm transformation. These challenges - termed the circularity challenge and the norm-reducibility challenge - target the first two theoretical assumptions about norm dynamics mentioned above. In response to these challenges, the paper first argues that testimony, broadly construed, offers a source of non-circular evidence concerning historical norm transformations. The paper then distinguishes between identity-instituting and identity-vindicating norm transformations, and uses this distinction to defuse the second, norm-reducibility challenge.

Section Four turns, finally, to the evaluative extension of the thesis of norm transformation. The section frames this extension in terms of the localization of moral and legal responsibility for transformations in norms that contribute to mass atrocity. The section first argues that it is legitimate to localize-i.e. restrict to some subset of a larger set of qualified parties - attributions of moral responsibility for norm transformation in cases where specific mechanisms for transforming norms can be identified, and where those changes in norms have had a demonstrable effect on the precipitation or prolongation of large-scale wrongs. The section then argues that in cases of societywide norm breakdown, as may be found in so-called "extremely violent societies," localization of legal responsibility for mass violence faces a higher justificatory burden, for both historiographical and properly juridical reasons.

\section{Norms: Definition and Dynamics}

On 11 September 1940, Dr. Leonardo Conti of the Reich Interior Ministry addressed a letter to his former medical school teacher, Professor Gottfried Ewald. Conti's letter was occasioned by Ewald's critical evaluation and rejection of the secret Nazi euthanasia program, Aktion T4. ${ }^{2}$ The text of Conti's letter reads as follows:

Dear Professor Ewald,

With the deepest gratitude I acknowledge the receipt of your letter of 21 August. I still remember with great pleasure your lectures in Erlangen.

Your analysis contains much that is right, I'm sure. Nevertheless, I take a different view, although I cannot and will not set it down in writing at this time. I would only like to say, that I am fully convinced that the opinions of the entire German Volk concerning these things are undergoing a transformation, and I can very easily imagine that things which in one period are considered objectionable [verwerflich] can in the next period come to be regarded as the only right choice. This is something we have experienced countless times in the course of history. As the most recent example I would gently point to the sterilization law: here the process of a transformation in thought [Umformung des Denkens] is today already quite far advanced. ${ }^{3}$

Conti's letter has commonly been cited as evidence of professional complicity in the Holocaust. ${ }^{4}$ The letter is of interest here because of the remarkable historical articulation it offers of the thesis of norm transformation. Conti's letter contemplates transformations in two long-standing prohibitions within the medical profession: a prohibition on intentional medical killing and a prohibition on involuntary sterilization. In order to better understand these claims, we must first clarify the definition of norms.

\section{Defining Norms}

This paper proposes the following general definition of norms: 
Norms are practical prescriptions, permissions, or prohibitions, accepted by members of particular groups, organizations, or societies, and capable of guiding the actions of those individuals.

Several features of this definition demand elaboration. First, it is necessary to explain what "acceptance" of a norm entails. Second, it is necessary to explain the significance of the particularity, or domain-limitedness, of norms. Third, it is necessary to explain what it means for norms to guide actions, and in what ways this can occur.

In the first place, norms are accepted by individuals. This is the basis of the socio-empirical quality of norms-i.e. their status as social facts that can be studied via standard procedures of historical and social scientific inquiry. ${ }^{5}$ Philosophical accounts of norm acceptance vary considerably; this paper will not seek to defend any single one of them. ${ }^{6}$ What is crucial is that any adequate account must accommodate a range of different types of norm acceptance, extending from relatively formal and explicit acts of acceptance (as in the case of professional oaths, university honor codes, and so on) to relatively informal or implicit forms of norm acceptance (as in the case of norms governing fair dealing in monetary transactions or gift giving). ${ }^{7}$ This paper is committed, furthermore, to two specific claims about norm acceptance. First, there is a substantive difference between following a norm merely in order to avoid sanctions imposed on infractions, and following a norm in order to sustain or satisfy properly normative attitudes (such as obligation; felt-bindingness, and so on). That difference may constitute, and at least tracks, the difference between merely conforming with and actually accepting a norm. ${ }^{8}$ Second, although it may be the case that all norms are, in principle, linguistically expressible, it is not necessarily the case that every individual who accepts a certain norm must be able to give a clear verbal account of that norm's requirements. ${ }^{9}$

In the second place, norms are domain-limited. They circulate within particular groups, organizations, and societies. This feature of norms explains the significant role that norms play in sustaining shared identities within particular groups, organizations, or societies. ${ }^{10} \mathrm{It}$ is also crucial to efforts by historians and social scientists to use norms to explain patterns of collective, rather than merely individual, behavior. ${ }^{11}$ To be sure, the bounds of the collectivities within which particular norms circulate are rarely static. The discussion of norm dynamics below aims to account for some of the many ways in which those bounds can change.

Finally, norms have the power to guide actions. Exactly how norms perform this central, actionguiding function is contested. One problem is to understand the cognitive and conative conditions under which norms dispose individuals to pursue particular courses of conduct. A second problem is to establish distinctions among the different types of actions-ranging from compliant to defiant - that can rightly be said to be guided by a given norm. ${ }^{12}$ While these difficulties should not be discounted, the action-guiding power of norms is clearly central to both explanatory and preventive applications of the thesis of norm transformation. ${ }^{13}$ Importantly, this paper assumes what I call the priority of the practical point of view. Put simply, this assumption holds that properly characterizing the contributions of particular norms to the prevention, or precipitation, of mass atrocities requires considering how those norms contribute to individuals' first-personal deliberations over plans and courses of conduct.

How, then, does the definition of norms offered here enrich our understanding of Conti's claims concerning the prohibitions on intentional medical killing and involuntary sterilization? It does so in three ways. First, Conti is asking Ewald to believe that, despite continuing widespread acceptance of the prohibition on euthanasia within German society, this norm is likely soon to change substantially. This claim, in turn, rests on an implicit distinction between the norms accepted by medical professionals such as Conti and by members of society at large. Finally, Conti appears to be suggesting that his former teacher ought not only to accept the change in the norms concerning euthanasia, but to act upon it-either in his role as a professor, or as a hospital administrator, or both. ${ }^{14}$

Ultimately, the claims set out in Conti's letter are not just claims about norms, but claims about transformations in norms. In order to fully understand these claims, it is necessary to turn from the definition to the dynamics of norms. 
Norm Dynamics

The topic of norm dynamics can be divided into two broad classes of questions. First, there are questions about the categorization of different types of transformations in norms. Second, there are questions about the empirical conditions under which norms are more or less likely to undergo transformations of these several types. The analysis offered in this section focuses on questions of the first kind. Specifically, it seeks to distinguish between norm inversion, norm breakdown, and norm emergence.

\section{Norm Inversion}

Norm inversions occur when individuals who previously accepted prohibitions on certain actions come to regard those same actions as required, or vice versa. It is possible, in principle for lone individuals to experience such radical transformations in normative attitudes and commitments, without thereby participating in broader group- or society-level inversions. Nevertheless, historical and social scientific claims about norm inversion typically refer to changes in norms accepted in the aggregate by members of particular groups, organizations, or societies. ${ }^{15}$

Conti's letter to Ewald offers a remarkably apt description of the dynamics of norm inversion. As Conti writes with respect to the existing prohibition on intentional medical killing: "things which in one period are considered objectionable can in the next period come to be regarded as the only right choice." The last part of this claim makes clear that Conti has in mind not merely the erosion of a prohibition, but rather a shift from a prohibition to a prescription, or normative requirement. It is also evident from Conti's letter that he anticipates not just individual, but grouplevel inversions of norms: first among members of the medical profession, ultimately among "the entire German Volk."

\section{Norm Breakdown}

Norm breakdowns occur when previously accepted norms cease to guide actions in fact, and cease to be available as guides to action in principle. These two types of transformation are logically distinct, but in practice they often occur together. ${ }^{16}$ When previously prevailing norms cease to be reflected in the publically observable actions of large numbers of individuals within a particular group, those norms tend to become less useful as guides to action for other members of that group. In the accounts of norm breakdown among German professionals under National Socialism offered by Konrad Jarausch and Berel Lang, just this dynamic is described. ${ }^{17}$

Like other kinds of norm transformations, breakdowns in norms are generally identified at the level of groups or populations. However, they cannot be fully understood without considering the beliefs and actions of individual actors. When norms break down, they lose their power to guide the decisions and actions of individual actors. This can occur for one of a number of reasons. Sometimes requisite motivational factors, such as empathy or a sense of fairness, fade. Other times norms, and the systems of norms to which they belong, become too complicated or convoluted to guide action. Wartime brutalization offers a reason of the first kind for norm breakdown. ${ }^{18}$ The existence of secret or contradictory laws within a repressive state offers a reason of the second kind. ${ }^{19}$

\section{Norm Emergence}

Norm emergence refers to a range of pathways and processes by which new norms arise and gain acceptance within particular populations. In this way, norm emergence contrasts with both norm inversion and norm breakdown - each of which starts from a condition in which a particular norm is already accepted by individuals belonging to a particular group, organization, or society.

Conceptual distinctions among different modes of norm emergence have only recently begun to receive sustained attention from scholars. Political scientists have described cases of grafting of new norms onto already existing norms, and have emphasized the importance of the work that norm entrepreneurs do in facilitating norm emergence..$^{20}$ Philosophers have analyzed phenomena such as the tendentious introduction of norms, and have modeled non-coercive paths of emergence for particular cooperation- and coordination-facilitating norms. ${ }^{21}$ 
Perhaps the most interesting trend in the study of norm emergence has been the rapid increase, over the past decades, in case studies of the development of particular norms in international law and politics. ${ }^{22}$ Unlike more general discussions of norm dynamics, many of these case studies aim to show how the development of specific norms has helped, or might help, to prevent mass violence. In order to better assess such claims we should turn now to examine in more detail the thesis of norm transformation.

\section{The Thesis of Norm Transformation}

The thesis of norm transformation combines claims about the explanation and the prevention of large-scale crimes. It holds, first, that individual and institutional participation in such crimes is at least partially explained by transformations in basic norms that structure social and political life. It holds, second, that preventing future occurrences of such crimes requires changing norms that currently guide the actions of particular individual and institutional actors.

Efforts by scholars and policymakers to use the thesis of norm transformation to explain, or prevent, particular instances of genocide and mass atrocity will be referred to here as applications of this thesis. This section will analyze several representative explanatory and preventive applications of the thesis of norm transformation. One aim of this analysis is to show how the general account of norms and norm dynamics offered above can enrich existing applications of this thesis. Another aim is to identify the basic theoretical assumptions underlying such applications.

\section{Explanatory Applications}

Reflecting on the Rwandan genocide in a 2004 article, political scientist Lee Ann Fujii directly invokes the thesis of norm transformation. "Put simply," she writes, "genocidal leaders had to transform the normative environment [in Rwanda] such that actions that were once considered verboten (such as killing thy neighbor) could be viewed as not only legitimate but imperative."23 Fujii offers a social psychological explanation for why such a transformation in norms should accompany genocide. "Norms," she avers, "become more important when reality is confusing, contradictory, or changing. The more ambiguous the situation, the more likely people are to rely on norms as guides for behavior; and the clearer the prescription of a given norm, the more likely people will follow that norm and not others." ${ }^{24}$ Throughout her paper, Fujii scans historical records and first-person accounts for clues to the particular mechanisms by which "genocide became normalized." 25

Fujii's invocation of the thesis of norm transformation calls attention to three theoretical assumptions that underlie explanatory applications of this thesis. The first assumption is that it is possible to reliably identify differences in the norms accepted by particularly situated individuals across two or more moments in time. The second assumption is that norms have a fundamental, or non-reducible, power to guide the actions of individuals, and consequently to pattern the conduct of groups. The third assumption is that it is possible to pinpoint specific mechanisms by which particular changes in norms have been, or might be, attained.

These three assumptions are not restricted to Fujii's application of the thesis of norm transformation. The letter from Dr. Conti discussed above manifests these assumptions. Turning to a more contemporary, and scholarly, literature, Christopher Browning's influential analysis of participation by "ordinary men" in mass killings on the Eastern Front during the Second World War embodies these assumptions. ${ }^{26}$

Consider the first assumption identified above. Browning's study of the members of Reserve Police Battalion 101, and his reasons for rejecting the idea that racist ideology or wartime brutalization might help to explain their participation in mass atrocity, are too familiar to require recapitulation here. What is worth noting is that Browning identifies not one, but two inversions in norms accepted by members of this particular unit at different moments in time. Browning first posits an inversion in norms regarding killing prior to participation by members of the Police Battalion in mass shootings in German-controlled territory in Eastern Europe. He then posits a second inversion, in fact a reversion, in the decades following WWII. Browning writes:

to concede that the morally inverted world of National Socialism - so at odds with the political culture and accepted norms of the 1960s-had made perfect sense to them at the time, would 
be to admit that they were political and moral eunuchs who simply accommodate to each successive regime. That was a truth with which few [former members of Reserve Police Battalion 101] either wanted or were able to come to grips. ${ }^{27}$

In order to see how the second assumption about norms is implicit in explanatory applications of the thesis of norm transformation, it is helpful to consider cases of apparent norm breakdown. Argentinean legal scholar Carlos Santiago Nino offers a helpful example in his discussion of "institutional anomie" during the Dirty War in his home country. Nino suggests that "judicial recognition of the legitimacy of coups d'état and the regime's ensuing laws is perhaps the clearest example" of such anomie. ${ }^{28}$ In helping to legitimate such practices, Nino argues, Argentinean courts allowed the erosion of crucial rule of law norms such as publicity and consistency in the law. ${ }^{29}$ Similar claims about breakdowns in norms governing the conduct of legal actors have been made by scholars of legal institutions under National Socialism. ${ }^{30}$ In each of these cases, the assumption is that relevant norms, had they not broken down, could have guided the implicated actors towards substantially different courses of conduct.

Consider, finally, the assumption that it is possible for scholars to pinpoint specific mechanisms by which particular changes norms have been, or might be, attained. Here it is appropriate to return to Fujii's 2004 analysis of the Rwandan genocide. Fujii identifies three distinct stages in the emergence of what she calls a "genocidal norm." 31 Each stage is associated with different mechanisms for provoking norm transformation. First there was a stage of spreading a message of social division and threats to the Hutu population from Tutsis. Second was a stage of producing objective evidence of those threats, through staged attacks, killings, and so on. Third was a stage of making the threats appear imminent, so as to require immediate action. ${ }^{32}$

Several of the specific mechanisms for norm transformation that Fujii singles out in these several stages have clear analogues in other historical cases of genocide. These include disseminating hate propaganda $^{33}$ and staging "enemy" attacks. Exactly how strong the causal connections between such acts and subsequent episodes of mass violence are is contested. ${ }^{34}$ Even where scholars point to different events as contributing to the inversion, emergence, or breakdown of norms, however, they share the assumption that it is possible to pinpoint specific mechanisms or processes that contribute to such transformations.

\section{Preventive Applications}

Preventive applications of the thesis of norm transformation rest on the same three theoretical assumptions about norm dynamics as explanatory applications. A representative example comes from legal scholar Mark Osiel's 2009 book, Making Sense of Mass Atrocity. After asking how changes in the law might "help created and cultivate within modern armies the institutional characteristics enabling them to steer clear of mass atrocity," Osiel suggests that one strategy might be to introduce laws imposing civil liabilities on officers whose subordinates take part in atrocities. The imposition of civil liabilities, Osiel suggests, avoids the problems of procedural justice that comparable criminal liabilities would encounter. ${ }^{35}$ At the same time, this change in the law directly counters existing social norms against "snitching" on fellow members of one's military unit. ${ }^{36}$

Osiel's proposal clearly depends upon the theoretical assumption that it is possible to reliably identify differences in the norms accepted by particularly situated individuals across two or more moments in time. In this way this preventive application of the thesis of norm transformation parallels the explanatory applications discussed above. What is different in this and other preventive cases is that the first of these two periods of time is defined as the present, and the second as some point in the future. ${ }^{37}$

The new norm Osiel advances is aimed primarily at individuals, and is closely tied to concrete sanctions (in the form of fines) for violations. Neither of these features is essential to preventive applications of the thesis of norm transformation. To see this, it is useful to turn to the emerging norm of Responsibility to Protect (R2P), and consider its claims to guide actions.

Unlike Osiel's proposed legal norm, R2P aims chiefly to guide the actions of states, rather than single individuals. And unlike Osiel's proposed norm, R2P aspires to guide actions even in the absence of effective enforcement mechanisms. Further clarity comes from distinguishing 
between primary and secondary bearers of responsibilities under R2P. Primary bearers of such responsibilities are individual states and state leaders. Secondary bearers are the various state and non-state actors composing the international community, who are tasked with taking up protective responsibilities when and where primary bearers fail to uphold them.

Crucially, scholars of R2P avoid describing protective actions by secondary bearers as punishments for failures by primary bearers to fulfill their responsibilities. ${ }^{38}$ Furthermore, as Luke Glanville has pointed out, there are currently no legal penalties prescribed for failures by secondary bearers to act in cases of malfeasance by primary bearers of responsibility. ${ }^{39}$ What this example shows is that, while preventive applications of the thesis of norm transformation depend on the assumption that norms have the power to guide actions, both the status of the actors guided by such norms and the schemes of accountability supporting such guidance can vary substantially.

Preventive applications of the thesis of norm transformation commonly give special attention to the mechanisms by which desired transformations are to be achieved. In political science, as noted above, scholars have offered numerous studies of the efforts of norm entrepreneurs to change norms in order to prevent war and civil conflict. ${ }^{40}$ In addition to highlighting the accomplishments of heroic individuals, such studies suggest that particular events in the domestic or international sphere may serve as catalysts for preventive norm transformations. In each of these cases, authors assume that it is possible to pinpoint specific mechanisms that have caused, or might in the future contribute to, preventive transformations in norms.

\section{Two Challenges to the Thesis of Norm Transformation}

The previous section surveyed some representative explanatory and preventive applications of the thesis of norm transformation, and identified three basic theoretical assumptions underlying such applications. This section will consider challenges to two of those assumptions. The first challenge, called here the circularity challenge, targets the assumption that it is possible to reliably identify differences in the norms accepted by particularly situated individuals across two or more moments in time. The second challenge, called here the norm-reducibility challenge, targets the assumption that norms have a fundamental, or non-reducible, power to guide the actions of individuals, and thereby pattern the conduct of groups.

\section{The Circularity Challenge}

Explanatory applications of the thesis of norm transformation rest in part on the assumption that it is possible to reliably identify differences in the norms accepted by particularly situated individuals across two or more moments in time. The circularity challenge casts doubt on this assumption. It raises questions about the verifiability of claims about the existence of particular at any given moment in time. Although charges of circularity can be leveled at claims about the existence of norms in the present day, such charges are strongest when applied to historical claims about norms or changes in norms. For this reason, it will here be treated as an historiographical challenge to the thesis of norm transformation.

Claims about the existence of norms are susceptible to charges of circularity because of the evidentiary gap that separates the observed conduct of actors - i.e. the actions that individuals undertake - from the unobservable cognitive and conative states of actors - i.e. the beliefs and attitudes with which they undertake them. In everyday life it is common to infer information about relevant beliefs and attitudes from the actions of individuals. But in the case of purportedly normguided conduct, such inferences threaten to produce a circular course of reasoning, in the following manner. First, observed patterns of behavior are taken as evidence of the existence of norms (and, by extension, the acceptance of those norms by individuals). Second, these same inferred norms are relied on to explain, or account for, those observed patterns of behavior. ${ }^{41}$

Some of the most promising strategies for confirming the existence of norms in present-day contexts are not available in cases of norms supposed to have existed in the past. Cristina Bicchieri, a leading theorist of social norms, has pioneered experimental methods for identifying, and measuring the strength of, such norms in present-day political societies. ${ }^{42}$ These methods depend on the experimenters' ability to control the beliefs subjects have about the types of interactions they 
are involved in, as well as the experimenters' ability to change the material incentives that subjects have for certain kinds of behavior. So, in experiments designed to analyze norms of fairness, subjects may be selectively fed information about the past behavior of their experimental partners; or they may be told that the experiment has been designed in such a way as to prevent partners from detecting unfair divisions of monetary rewards. ${ }^{43}$

Experiments of this kind are clearly not feasible when it comes to the study of norms supposed to have existed in historical contexts. ${ }^{44}$ There are, however, other sources, besides the actions of historical individuals themselves, which can provide evidence of the existence of norms that might help to explain those actions. Two of the most important of these sources, already much discussed in the literature on genocide and mass atrocity, are documents and testimony. ${ }^{45}$

Holocaust scholars have extensively debated the relative merits of documents and testimony as sources of historical knowledge about this genocide. Leading figures such as Raul Hilberg and Robert Wolfe have insisted on the primacy of documents created by the National Socialists themselves as sources of information concerning the plan and execution of their genocidal policies. ${ }^{46}$ Such documents do indeed provide evidence of norms, and changes in norms. One important example concerns the language rules developed by various parties within the military and political hierarchies to conceal the truth about the policies of deportation and mass killing, both from the targets of such policies and from third parties. The existence of letters and memos in which particular officials were reprimanded for failing to conform to such language rules seems to provide non-circular evidence for the existence of such rules, which, as I have argued elsewhere, may have taken on the status of social norms. ${ }^{47}$

For Hilberg, the evidentiary advantage of documents over testimony was decisive. As Yehuda Bauer has argued, however, prioritizing documents produced by the authors of the plan of destruction threatens to distort the historical record in another way, by leaving out large segments of the experience of the groups and communities occupied or terrorized by the National Socialists and their allies. Treating testimony as a source of historical knowledge is not unproblematic, Bauer admits, but it is a mistake to think that historiographical quality is unequivocally improved by excluding it. ${ }^{48}$

If testimony is admitted as a source of historical knowledge, then it provides a second route to overcoming the circularity challenge to claims about the existence of norms in historical

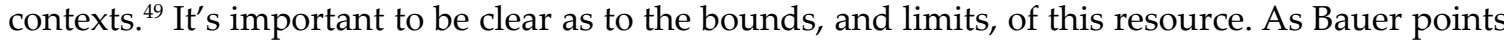
out, testimony will be most reliable when multiple individuals provide consistent testimony concerning the existence or influence of a particular fact or event. ${ }^{50}$ In the context of discussions of norms, numbers are important in part because it is always possible for single individuals to be mistaken about what norms are accepted by other individuals in a particular context. An example may help to illustrate this point. Consider a case reported by the German Jewish academic Victor Klemperer in his important diaries of daily life in Dresden under National Socialism. In his diary entry for June 13,1934, Klemperer shares an anecdote concerning the consequences of boycotts of Jewish-owned business in three neighboring towns outside Dresden:

In Falkenstein one is not allowed to buy from the "Jew." And so the people in Falkenstein travel to the Jew in Auerbach. And the Auerbachers in turn buy from the Falkenstein Jew. However, on bigger shopping expeditions the people from the one-horse towns travel to Plauen, where there's a larger Jewish department store. If you run into someone from the same town, no one has seen anyone. Tacit convention. ${ }^{51}$

Do Klemperer's observations count as evidence of the existence of an emerging rule of behavior in this region at this period, and if so, what is the strength that evidence? Because this is a diary entry, rather than a piece of courtroom testimony or an oral reminiscence from well after the fact, certain kinds of criticisms do not apply. Klemperer's report could hardly be motivated by a desire to exculpate himself for some wrongdoing (as courtroom testimony might); nor can this report be distorted by the clouding effects of time. Nevertheless, it is a genuine question whether Klemperer was correct in his claims about both the actions, and the intentions, of non-Jewish residents of these towns, and the evidentiary quality of his claim would be heightened if it were joined by 
testimony from other individuals from the area confirming this point. To gain fully dispositive evidence of a norm governing this specific practice, it might also be necessary to acquire testimony regarding certain counter-factual claims, such as the claim that at least some of the shoppers in this region would have acted in this way even if the instrumental reasons for doing so (i.e. fear of stigmatization or criticism) were removed..$^{52}$ To my knowledge, such supplementary testimony does not exist concerning this particular, highly localized convention. It should, however, be possible to find multiple testimonies to the existence of other kinds of norms during the Holocaust and other episodes of genocide and mass atrocity. ${ }^{53}$ In this way, then, it seems possible to overcome the circularity challenge to explanatory applications of the thesis of norm transformation using documents and testimony.

The Norm-Reducibility Challenge

Whereas the circularity challenge targets the assumption that it is possible to reliably identify differences in the norms accepted by particularly situated individuals across two or more moments in time, the norm-reducibility challenge targets the assumption that norms have a fundamental, or non-reducible, power to guide the actions of individuals, and consequently to pattern the conduct of groups. Here I will focus on the argument for norm reduction recently set forth by political scientist Kristen Renwick Monroe.

In her 2012 book, Ethics in an Age of Terror and Genocide, Monroe aims to show how individuals' identities, worked out in the context of specific social relationships, constrain the range of choices available during moral decision-making. ${ }^{54}$ Three concepts are crucial to Monroe's model of moral choice. First is the concept of identity. Drawing on the findings of social identity theory within social psychology, Monroe suggests that differences in identity do much to explain the different actions of perpetrators, bystanders, and rescuers in contexts of genocide and mass atrocity. One of the key claims here is that individuals who conceive of their identity as more extensive, i.e. as bearing broader connections with other individuals across space and time, are more likely to perceive threats to the well-being of those others as morally salient, and thus as presenting an opportunity for moral choice. ${ }^{55}$

While identity constrains determinations of moral salience, the determinations themselves are reached through the cognitive process of categorization. Monroe defines this second key concept as "the process by which ideas and objects are recognized, differentiated, or distinguished from one another and then understood." ${ }^{56}$ Her model construes cognitive categorization as operating in several distinct stages. First, out of the manifold data of experience, cognitive categorization settles the particular ways in which particular situations will be framed for particular actors. Particular modes of framing, in turn, lead to the activation, or suppression, of particular scripts for behavior. These scripts, finally, count as the proximate causes of observed conduct. ${ }^{57}$

The third major concept in Monroe's model of moral choice is that of cognitive stretching. This concept seeks to capture the fact that patterns of categorization can change over time, in response to a variety of environmental or social factors. Put differently, cognitive stretching seeks to explain how situations or events that at one time seem to be morally salient for particular individuals can subsequently cease to be categorized in this way, or vice-versa. ${ }^{58}$

Monroe clearly believes that it is possible to reliably identify differences in the norms accepted by particularly situated individuals across two or more moments in time. She also clearly believes it is possible to pinpoint mechanisms by which transformations in norms are brought aboutciting for example Christopher Browning's account of the effects of isolation, propaganda, and manipulation on German police officers recruited for mass killings. ${ }^{59}$ Monroe thus accepts two of the three theoretical assumptions behind the thesis of norm transformation. Her empirically grounded model of moral choice challenges the remaining assumption, however, by suggesting that norms are not fundamental as guides to action.

To the extent that Monroe's model explicitly addresses the ability of norms to guide decisions and actions, it suggests that they do so non-reflectively. Her entire account is designed to call into question moral theories that focus on deliberation and rational reflection on right and wrong action. Indeed, the central framing device for her study is the idea that both bystanders and resisters of genocide tend to claim that they had "no choice" in acting or failing to act. ${ }^{60}$ 
A second, and more consequential, feature of Monroe's model is the claim that the acceptance of norms often occurs unreflectively, and may be difficult to raise to the level of conscious awareness or reflection. Monroe argues that an individual's identity, or self-conception, largely determines both which facts about the world that individual recognizes as morally salient, and which choices seem available to that individual in the face of such facts. ${ }^{61}$

Both of these claims are, in principle, compatible with the thesis of norm transformation, though they provide a very different picture of both the acceptance of norms and the way in which norms guide action than has been presented so far in this paper. There is, however, a case to be made that, on Monroe's model, norms themselves are not decisive for understanding moral choice in the context of mass atrocity. Norms are not fundamental to the explanation of individual and group conduct during large-scale crimes, since both cognitive processes of categorization and, before this, social processes of identity formation seem to be doing most of the explanatory work. And norms are not fundamental to the prevention of large-scale crimes, since what really seems to be important is changing individuals' self-conceptions, and in this way altering the categories they deploy and the facts or events that they take to be legally or morally salient. ${ }^{62}$ This, in my view, is the strongest statement of the challenge that Monroe's theory offers to the thesis of norm transformation.

In responding to this challenge, I will argue that the acceptance of norms is not merely a consequence of, but also often constitutive of, individual and group identities. ${ }^{63}$ That is to say, changes in the set of practical prescriptions, permissions, or prohibitions that one accepts can serve as conditions for claiming, or maintaining a claim upon, particular identities. Two particular types of changes in norms are worth distinguishing here. First are identity-instituting norm transformations. These are changes in norms that serve as conditions for the adoption of new identities. Second are identity-vindicating norm transformations. These are changes in norms that serve as conditions for preserving, in the face of some significant threat, existing identities.

How do identity-instituting norm transformations bear on theories of genocide and mass atrocity? Here again the National Socialist euthanasia program, Aktion T4, is instructive. As Henry Friedlander has shown, the ideas and ideologies that stood behind the euthanasia program had existed in Germany (and indeed, in countries outside of Germany, including the United States) well before the rise of the Nazi movement. ${ }^{64}$ In terms of changing norms, particularly legal norms, to reflect these ideas and ideologies, however, it was specifically the political takeover of power by Hitler that "made the implementation of the race hygiene utopia possible." ${ }^{65}$ It is this utopian aspect of the Nazi policy towards the disabled, emphasized by historian Eric Weitz, that makes it appropriate to consider the relevant changes in laws regarding so-called "life unworthy of life" as a form of identity-instituting norm transformation: a change in norms coinciding with, and regarded at the time as a condition for, the development of a new Völkisch identity. ${ }^{66}$ Claudia Koonz has perhaps gone furthest in suggesting that it was identity-instituting changes in norms, rather than the broader racist or ableist ideologies with which those changes were connected, that distinguished National Socialist political culture from that of other contemporary political societies. ${ }^{67}$

Shifting to identity-vindicating norm transformations, it is useful to consider the Nuremberg Code of medical ethics, promulgated in the first so-called "Successor Trial" at Nuremberg. While chief prosecutor Telford Taylor considered it possible to "pass very briefly over matters of medical ethics" in his opening statement at this Doctors' Trial, retrospective accounts have called the Nuremberg Code "the most important document in the history of the ethics of medical research." 68 Chiefly at issue in the Nuremberg Code is the requirement that doctors obtain voluntary and adequately informed consent from prospective research subjects. As historian Paul Weindling has pointed out, a major aim of the scientists and physicians who assisted Taylor in developing his prosecutorial strategy was to avoid "too strong a denunciation of Nazi medicine [which] might jeopardize their own position," and to articulate "conditions under which risky experimentation was ethically permissible." ${ }^{69}$

The development of the principle of informed consent, on this reading, is an example of an identity-vindicating norm transformation. It is a norm that had not been clearly articulated, or broadly accepted, prior to WWII, but which became part of the basis of the continuing legitimacy of the medical profession after that conflict. Importantly, this change in norms was not so radical as to 
completely disrupt or destroy the existing identity of medical professionals; it allowed physicians to continue drawing on a tradition of medical experimentation designed to improve future care, even while suggesting that certain past methods of research were not longer permissible. ${ }^{70}$

The discussion of identity-instituting and identity-vindicating norm transformations offered above has shown that norms, and changes in norms, cannot be eliminated from an identity-based account of moral choice on the basis of the non-fundamentality objection. This finding is significant for both explanatory and preventive applications of the thesis of norm transformation. It also helps to establish the legitimacy of evaluative applications of the thesis of norm transformation, to which I now turn.

\section{Extending the Thesis of Norm Transformation}

Scholars of genocide and mass atrocity regularly register tensions between efforts to explain, prevent, and pursue accountability for participation in large-scale crimes. ${ }^{71}$ Some go further, and suggest that questions of accountability, or moral and legal responsibility for large-scale crimes, necessarily conflict with efforts to understand and prevent such crimes, and consequently ought to be deferred. ${ }^{72}$

While recognizing the reasons behind these calls for caution, this paper takes a different view. The thesis of norm transformation establishes a fundamental continuity between explanatory, preventive, and evaluative approaches to genocide and mass atrocity. If the three basic assumptions underlying the explanatory and preventive applications of this thesis are indeed tenable-if it is possible to non-circularly identify changes in norms, if norms play a non-reducible role in guiding action, and if it is possible to identify specific processes through which norms have been, or might be, transformed - then it is important to consider the implications for efforts to hold individuals and groups accountable for participation in large-scale crimes. This section briefly discusses two such implications. The first concerns strategies for localizing moral responsibility for mass atrocity. The second concerns obstacles to localizing legal responsibility for such wrongs.

\section{Localization of Moral Responsibility}

To localize responsibility for wrongdoing is to restrict attributions of responsibility to some subset of a larger set of qualified parties. Some ways of localizing responsibility - such as holding executives responsible for the success or failure of corporations and other institutions-typically strike us as legitimate. Other ways of localizing responsibility - such as scapegoating in its various guisesare by definition illegitimate. A key factor in assessing the legitimacy of any proposal to localize responsibility consists in the degree of effective control that particular individuals exercised, or were capable of exercising, over the decisions and actions of other individuals. ${ }^{73}$

This paper proposes the following principle for localizing moral responsibility for mass atrocities. Where specific mechanisms for transforming norms can be identified, and where those transformations in norms have had a demonstrable effect on the precipitation or prolongation of large-scale wrongs, then it may be appropriate to hold individuals involved in designing or implementing such mechanisms morally responsible for doing so.

Two examples will clarify the range and limits of this principle. The first, already referred to above, is the development of a coded language for describing the torture and killing of the disabled, Jews, political prisoners, and other persecuted groups under National Socialism. The second is the profusion of hate propaganda that commonly accompanies large-scale wrongs.

Each of these mechanisms has been identified as contributing to what James Waller calls "a culture of cruelty that helps [perpetrators] initiate, sustain, and cope with their extraordinary evil." ${ }^{14}$ If such assessments are accurate, then it seems appropriate to hold individuals responsible for developing and deploying such mechanisms. Localizing responsibility for changes in norms in this way does not absolve other individuals of responsible from particular wrongful acts, such as killing, torture, or theft. Instead, it introduces a new layer of responsibility specifically aimed at addressing the specific wrong of transforming the normative landscape. In assessing responsibility for such norm transformations, standard criteria for moral responsibility, including intent, knowledge, and ability to actually accomplish the transformations contemplated, will need to be considered. But there is no reason to think that these criteria pose greater barriers to attributions of 
moral responsibility for instigating norm transformations than they do for assessing responsibility for other kinds of contributions to mass atrocities. ${ }^{75}$

Importantly, this principle pushes for the localization of moral, rather than legal, responsibility for norm transformations. It is unlikely that international courts or tribunals would ever countenance a crime of transforming the normative landscape as such - though certain mechanisms for doing so (such as the spread of hate propaganda) have been criminalized in international law. ${ }^{76}$ In part, this is because of the different epistemologies, or ways of knowing and proving, employed by law and by other moral and historical discourses. ${ }^{77}$ In part, this is because courts and justice systems simply are not designed to deal with the problem of assigning responsibility in cases where infractions are normal, rather than exceptional, as the next section will suggest.

\section{Rethinking Localization of Legal Responsibility}

A second evaluative implication of the thesis of norm transformation can be framed in the form of a critique of current practices of localizing legal responsibility for mass atrocity. This critique builds on historian Christian Gerlach's doubts about the explanatory value of the concept of genocide. ${ }^{78}$ Gerlach contends that thinking about mass violence in terms of genocide undermines, rather than enriches, historical understanding. More specifically, he argues that "genocide is an actionoriented model designed for moral condemnation, prevention, intervention, or punishment," which unduly "restricts the analysis" of large-scale violence. ${ }^{79}$ Gerlach's positive project is to show that mass violence is more pluralistic in its targets and perpetrators, more complex in its planning and execution, than genocide-oriented studies acknowledge. ${ }^{80}$

Gerlach's analysis of the complex causes of mass violence embraces the thesis of norm transformation. In extremely violent societies, he observes, "ethical norms and values are devalidated not only among persecutors or profiteers, but also among the vulnerable groups. This leads to atomization, betrayal, corruption, opportunism, ignorance, and cruelty." ${ }^{11}$ What is novel is Gerlach's emphasis on cross-cutting breakdowns in norms governing social, political, and religious life.

This way of understanding mass violence, with its emphasis on "social processes that can only partially be controlled by any government," runs counter to efforts to localize legal responsibility within a relatively small group of governmental actors. ${ }^{82}$ As explained above, one criterion for the legitimacy of any effort to localize responsibility is the vesting of control over events in particular individuals. This is just what the notion of extremely violent societies denies.

Gerlach suggests that the concept of genocide itself localizes legal responsibility for largescale crimes in ways that may be justified on instrumental, though not historiographical, grounds. "Punishment has to be limited," he writes. "To admit that all sorts of groups, organizations and individuals participated in mass violence runs counter to the attempt to restore social peace and to find values based on which society may live together in [the] future." 83

If the general analytical framework of this paper is correct, then Gerlach's perspective on the relationship between of historical analysis and policies aimed at prevention or punishment seems too pessimistic. These different undertakings can and should inform each other; challenges encountered in the course of the one endeavor should prompt revisions in approaches to the other. Legal scholar Mark Drumbl argues to this effect in his book Atrocity, Punishment, and International Law. ${ }^{84}$ There, Drumbl suggests that the model of individual criminal responsibility, grounded in assumptions about the prosecution of socially deviant action, is ill fitted to cases of mass atrocity characterized by widespread societal participation and support. He proposes a more pluralist approach to attributions of legal responsibility, one that accommodates a variety of democratically responsive forms of criminal and civil proceedings.

It is beyond the scope of this paper to assess Drumbl's specific policy suggestions. One takeaway from his analysis, however, is that localization of legal responsibility for mass atrocities in a small group of leading actors can be as problematic from a legal perspective as it is distortive from a historiographical point of view. That is a finding that coincides with this paper's basic claim that explanatory, preventive, and evaluative applications of the thesis of norm transformation are, in principle, compatible. 


\section{Conclusion}

The thesis of norm transformation is powerful and provocative. It provokes by asking us to acknowledge the mutability of the basic norms that structure political societies-including our own societies. In return, it offers a powerful framework for making sense of crimes that strain comprehension and defy censure.

The thesis of norm transformation does not compel a choice between explanatory, preventive, and evaluative priorities in the face of mass atrocity. Instead, it posits a fundamental continuity between these different aims. It suggests that they are not just compatible, but may even be complementary.

Important questions remain about how the thesis of norm transformation should be applied with respect to particular episodes of genocide and mass atrocity. Some of these questions are historiographical. Others concern institutional design. Still others are legal or moral. Rather than seeking to settle these questions, this paper has clarified, defended, and extended the set of concepts on which scholars from diverse disciplinary backgrounds can draw when pursuing answers. Ultimately, Raphael Lemkin's observation concerning genocide applies to large-scale crimes more generally: "the examination of the problem is not limited to one branch of science, but claims the support of many." 85

\section{Acknowledgments}

This paper incorporates research conducted while the author was a Raab Foundation Visiting Fellow at the Mandel Center for Advanced Holocaust Studies at the United States Holocaust Memorial Museum. The paper has benefited from comments offered by Istvan Pal Adam, as well as by two anonymous reviewers.

\section{Endnotes}

1 See for example Christopher Powell, Barbaric Civilization: A Critical Sociology of Genocide (Ithaca, NY: McGillQueen's University Press, 2011), 59; Christian Gerlach, "Extremely Violent Societies: An Alternative to the Concept of Genocide," Journal of Genocide Research 8, 4 (2006): 455-471; Richard Ashby Wilson, Writing History in International Criminal Trials (New York: Cambridge University Press, 2011).

2 Under this program, physically and mentally disabled German children and adults were selected by physicians for killing in state-regulated hospitals and medical establishments. See Dick de Mildt, In the Name of the People: Perpetrators of Genocide in the Reflection of their Post-War Prosecution in West Germany (London: Martinus Nijhoff, 1996); also Henry Friedlander, The Origins of Nazi Genocide: From Euthanasia to the Final Solution (Chapel Hill: University of North Carolina Press, 1995).

3 For the German text of this letter, see Thorsten Sueße and Heinrich Meyer, Abtransport der 'Lebensunwerten,' (Hannover: Verlag Clemens Koechert, 1988), 103-104. Cited in Robert Ericksen, Complicity in the Holocaust: Churches and Universities in Nazi Germany (New York: Cambridge University Press, 2012), 161-163. The translation offered here is my own.

4 Ericksen, Complicity, 161-163; see also Robert Jay Lifton, The Nazi Doctors: Medical Killing and the Psychology of Genocide (New York: Basic Books, 2000), 82-87.

5 In focusing on accepted norms, I follow Robert Goodin et al in distinguishing between accepted norms, on the one hand, and the possible category of objective norms, whose existence does not depend on acceptance, on the other. See Robert Goodin, Geoffrey Brennan, Nicholas Southwood, and Lina Eriksson, Explaining Norms (Oxford: Oxford University Press, 2013), 2-3.

6 Within the philosophical literature on norms, different theorists offer different accounts of norm acceptance. On one line of thinking, what is crucial is that norms be "internalized" -i.e. incorporated into individuals" identity, rather than merely regarded as external features of the social world. Another prominent view considers individuals' intentions, rather than their identity, to be the criterion for norm acceptance. On this view what matters is for actors to form and maintain the right sort of intentions with regard to the various norms they accept. See H.L.A. Hart, The Concept of Law (Oxford: Oxford University Press, 1961), 165-176; Margaret Gilbert, A Theory of Political Obligation (New York: Cambridge University Press, 2006), 197-204; Goodin et al, Explaining Norms, 3-4.

7 Cristina Bicchieri, Erte Xiao, and Ryan Muldoon. "Trustworthiness is a Social Norm, but Trusting is Not," Politics, Philosophy \& Economics 10, 2 (2011): 170-187. http://dx.doi.org/10.1177/1470594X10387260.

8 Goodin et al draw a similar distinction between following norms and merely (instrumentally) conforming with norms. I prefer to use the phrase "following a norm" to describe behavior that matches substantially 
the prescriptions, prohibitions, or permissions offered by a norm, whether or not that behavior is motivated in part by attitudes constitutive of acceptance of that norm. On my view, then, it makes sense to talk about norm following with and without acceptance, just as it makes sense to talk about norm violating with or without norm acceptance. See Goodin et al, Explaining Norms, 218.

9 Philosopher Allan Gibbard argues that norms must be, at least in principle, linguistically expressible. See Gibbard, Wise Choices, Apt Feelings (Cambridge, MA: Harvard University Press, 1992), 70.

10 This paper does not investigate differences in kinds of norms, such as legal, moral, and social norms, which might seem connected with this particularity requirement. Some suggest, for example, that moral norms are not domain limited, but rather universal in scope. Modifying this claim slightly, it might be thought that part of what it is to accept a moral norm is to form a belief that that norm ought to guide the actions of all human, or rational, or morally competent individuals. For the purposes of this paper, it will suffice to say that the particularity feature of norms does not rule out the possibility that some norms could win acceptance among all human, or rational, or morally competent individuals.

11 Goodin et al, Explaining Norms, 162-175; also Edna Ullmann-Margalit, The Emergence of Norms (New York: Oxford University Press, 1977). Like these authors, I adopt a form of methodological individualism, according to which explanations of the power of norms to pattern the conduct of groups must be rooted in claims about the influence of norms upon the decisions and actions of the individuals composing those groups.

12 Goodin et al distinguish between conforming and complying with norms, on the one hand, and between avoiding and acting opposite to norms, on the other. Arguably each of these types of action can be considered "norm-guided," where this means that the action in question would not be performed, or would not be performed in the same way, in the absence of a given norm. See Goodin et al, Explaining Norms, 195-196; 237-238.

13 A more explicit treatment of this point will be offered in Section 2.

14 For further contextualization of this point, see Ericksen, Complicity, 161-163.

15 Writing about perpetrators of mass atrocity, for example, James Waller suggests that such individuals occupy "an inverted moral universe, shaped by a process of brutalization, in which right has become wrong; healing has become killing; and life has become death." See James Waller, Becoming Evil: How Ordinary People Commit Genocide and Mass Killing (New York: Oxford University Press, 2002), 203.

16 On my view, the connection between breakdowns of norms in practice and in principle differs according to the type of norm in question: so that in the case of social norms, which I consider to be necessarily practice grounded, a change in real or perceived practices may in fact be sufficient to destroy a norm in principle, whereas in the case of properly moral norms, which are not grounded in real or perceived practices, this is not sufficient. The norms that make up codes of professional ethics, like the norms the compose legal codes, stand in a less clear connection with actual practices. For discussion of the practicegrounded character of social norms, see Paul Morrow, "Mass Atrocity and Manipulation of Social Norms," Social Theory and Practice 40, 2 (April 2014): 257.

17 Konrad Jarausch, The Unfree Professions (New York: Oxford University Press, 1990); Berel Lang, "The Third Reich and the Breakdown of Professional Ethics," in The Future of the Holocaust (Ithaca, NY: Cornell University Press, 1998), 92-104.

18 Waller 2002, 203.

19 This was the contention of Lon Fuller, the mid-century American legal scholar. See Lon Fuller, The Morality of Law (New Haven: Yale University Press, 1964), 65-70.

20 For "grafting," see David Lanz, "Why Darfur? The Responsibility to Protect as a Rallying Cry for Transnational Advocacy Groups," Global Responsibility to Protect Vol. 3 (2011), 243-244. There is a large literature on norm entrepreneurs; a good introduction can be found in Martha Finnemore and Kathryn Sikkink, "International Norm Dynamics and Political Change," International Organization 52, 4 (1998): 887917.

21 For the tendentious introduction of norms, see Gilbert, A Theory of Political Obligation, 199. For philosophical accounts of the emergence of norms, see Ullmann-Margalit, The Emergence of Norms; Brian Skyrms, The Evolution of the Social Contract (New York: Cambridge University Press, 1996); J. McKenzie Alexander, The Structural Evolution of Morality (New York: Cambridge University Press, 2010).

22 See e.g. Sarah Percy, Mercenaries: The History of a Norm in International Relations (New York: Oxford University Press, 2007); Kathryn Sikkink, The Justice Cascade: How Human Rights Prosecutions Are Changing World Politics (New York: Norton, 2011); Tuba Inal, Looting and Rape in Wartime: Law and Change in International Relations (Philadelphia: University of Pennsylvania Press, 2013); Alex Bellamy, Massacres and Morality: Mass Atrocities in an Age of Civilian Immunity (New York: Oxford University Press, 2012). 
23 Lee Ann Fujii, "Transforming the Normative Landscape: The Diffusion of a Genocidal Norm in Rwanda, Journal of Genocide Research 6, 1 (2004): 99-100. http://dx.doi.org/10.1080/1462352042000194737. The parallel between Fujii's phrasing and the description of norm inversion offered by Dr. Conti in his letter to Dr. Ewald is striking.

24 Fujii, “Transforming the Normative Landscape," 100.

25 Fujii, "Transforming the Normative Landscape," 113. In her more recent book, Killing Neighbors: Webs of Violence in Rwanda, Fujii disavows part of the analysis contained in this article. In particular, she notes that "while leaders and politicians can frame any conflict in ethnic terms," the reasons for which individuals within local communities participate in conflict may differ substantially, reflecting distinctively local social and political configurations. This change in Fujii's analysis does not diminish the fact that her 2004 article provides a particularly direct statement of the thesis of norm transformation. Since my ultimate aim in this paper is to address challenges to the various assumptions underlying that thesis, I believe it is appropriate to cite Fujii's 2004 article here. See Lee Ann Fujii, Killing Neighbors: Webs of Violence in Rwanda (Ithaca, NY: Cornell University Press, 2009), 180.

26 Christopher Browning, Ordinary Men: Reserve Police Battalion 101 and the Final Solution in Poland (New York: Harper Perennial, 1993).

27 Browning, Ordinary Men, 150.

28 Carlos Santiago Nino, Radical Evil on Trial (New York: Oxford University Press, 1996), 47.

29 Nino, Radical Evil, 48.

30 There is a large literature on this topic. For a good recent introduction, see Kenneth Ledford, "Judging German Judges in the Third Reich: Excusing and Confronting the Past," in The Law in Nazi Germany, eds. Alan Steinweis and Robert Rachlin (New York: Berghahn Books, 2013), 161-189.

31 It might be objected that Fujii's account was described above as giving an example of norm inversion. Norm inversion, however, itself entails the emergence of a new norm - and the mechanisms for promoting the emergence of an inverted norm are, in general, the same as the mechanisms for promoting the emergence of an entirely unprecedented norm.

32 Fujii, “Transforming the Normative Landscape," 112.

33 See Jeffrey Herf, The Jewish Enemy: Nazi Propaganda during World War II and the Holocaust (Cambridge, MA: Belknap Press, 2006).

34 Richard Ashby Wilson, "Inciting Genocide with Words," Forthcoming in Michigan Journal of International Law Vol. 36, N. 1 (2015). Accessed online at http://papers.ssrn.com/sol3/papers.cfm?abtract id=2439325.

35 Mark Osiel, Making Sense of Mass Atrocity (New York: Cambridge University Press, 2009), 203-217. I previously used this example from Osiel's book to illustrate a possible morally permissible instance of manipulation of social norms; here, I invoke this same proposal as one of a broader set of preventive applications of the thesis of norm transformation. See Morrow, “Mass Atrocity and Manipulation of Social Norms," 279.

36 Osiel, Making Sense, 210-213.

37 This should not be taken to discount the importance of historical accounts of preventive changes in norms.

38 Some opponents of R2P have seen such actions precisely as punishment. Venezuela's delegate to the 2005 UN World Summit remarked that R2P would lead to "States of the [global] South" being "stigmatized as systematic violators of collective human rights and punished through 'humanitarian intervention'." See U.N. GAOR, 59th Sess., 89th plen. mtg. at 24, U.N. Doc. A/59/PV.89 (Apr. 8, 2005). Cited in Jonah Eaton, "An Emerging Norm? Determining the Meaning and Legal Status of the Responsibility to Protect," Michigan Journal of International Law Vol. 32 (2010), 788-9.

39 There may, however, be certain reputational consequences of such failures. See Luke Glanville, "The Meaning of 'Responsibility' in the Responsibility to Protect," Griffith Law Review Vol. 20, N. 2 (2011), 492493. http://dx.doi.org/10.1080/10383441.2011.10854706.

40 Finnemore and Sikkink, "International Norm Dynamics and Political Change"; Michael Barnett, Empire of Humanity (Ithaca, NY: Cornell University Press, 2011).

41 Cristina Bicchieri, “Norms in the Wild," Descartes Lectures, University of Tilburg, Forthcoming. Used by permission.

42 Cristina Bicchieri, The Grammar of Society (New York: Cambridge University Press, 2005).

43 Bicchieri, Grammar of Society.

44 At best, experiments might try to replicate the situations faced by particular historical actors; but even then such experiments only provide insights into norms that might have been accepted by historical individuals, rather than providing evidence of the actual acceptance of such norms. The famous experiments of psychologists Stanley Milgram and Philip Zimbardo are explanatory in just this sense. 
45 Philosophers associate testimony principally with general questions in epistemology about the justificatory power of third-person claims. My focus here is not on testimony in this broad sense, but rather on testimony as a source of historical knowledge, as it is currently debated within the historiography of mass atrocity.

46 Raul Hilberg, Sources of Holocaust Research: An Analysis (Chicago: Ivan Dee, 2001); Robert Wolfe, "Nazi Paperwork for the Final Solution," in James Pacy and Alan Wertheimer (eds.), Perspectives on the Holocaust: Essays in Honor of Raul Hilberg (Boulder, CO: Westview, 1995), 5-6.

47 Some might object that such language rules are different in kind from norms, insofar as the only possible reasons the relevant historical individuals could have had for following them would be instrumental reasons, e.g. fear of sanctions for infractions. I see no in principle reason for supposing that properly normative attitudes (such as internalization, felt-bindingness, etc.) could not develop towards such language rules, however - in which case, according to the argument of this paper, it would be appropriate to classify them as a kind of norm. For a more extended investigation of such language rules, and of historical and conceptual reasons for regarding them as social norms, see Morrow, "Mass Atrocity and Manipulation of Social Norms," 268-278.

48 Yehuda Bauer, Rethinking the Holocaust (New Haven: Yale University Press, 2001), pp. 23-24. For a more recent, and highly instructive, discussion of the advantages and disadvantages of the increasing use of testimony as a source of historical knowledge amongst Holocaust scholars, see Henry Greenspan, Sara Horowitz, Éva Kovács, Berel Lang, Dori Laub, Kennneth Waltzer, and Annette Wieviorka, "Engaging Survivors: Assessing 'Testimony' and 'Trauma' as Foundational Concepts," Dapim 28, 3 (2014): 190-226.

49 See Zoë Waxman, "Transcending History? Methodological Problems in Holocaust Testimony," in The Holocaust and Historical Methodology, ed. Dan Stone (New York: Berghahn Books, 2012), 143-157. To be clear, I am using testimony here not in its narrow, juridical or quasi-juridical sense, but rather in the broader sense that includes diaries, memoirs, and other types of text and speech as well.

50 Bauer, Rethinking the Holocaust, 25.

51 Victor Klemperer, I Will Bear Witness, 1933-1941, trans. Martin Chalmers (New York: Modern Library, 1998), 67-68. Although norms and conventions are not synonymous, for historiographical purposes the same evidentiary problems arise.

52 I thank one of the anonymous reviewers of this paper for this point.

53 In order to keep the evidentiary bar from being pushed prohibitively high, it's important to note that some of the difficulties in gathering testimonial evidence concerning norms are not restricted to historical contexts, but rather arise from the very nature of what it is to inhabit the practical point of view. Within this point of view, real and apparent norms of many different kinds protrude, and it can be difficult to sort out exactly what normative beliefs and attitudes other individuals hold, and which of those normative beliefs and attitudes, if any, help to explain particular actions those individuals undertake. I take it that the proper historiographical response to this fact is to try to preserve the defeasibility of everyday claims about norms when reconstructing the role of norms in guiding the decisions and actions of historical individuals and groups.

54 Kristen Renwick Monroe, Ethics in an Age of Terror and Genocide (Princeton, NJ: Princeton University Press, 2012).

55 Monroe, Ethics, 21.

56 Monroe, Ethics, 347.

57 Monroe, Ethics, 255-260.

58 Monroe, Ethics, 23-24.

59 Monroe, Ethics, 22.

60 Monroe, Ethics, 8. Goodin et al cite Monroe as advocating the view that norms can sometimes prohibit even deliberation over certain kinds of actions. See Goodin et al, Explaining Norms, 252.

61 Monroe, Ethics, 306-7

62 An important caveat to this claim about Monroe's theory is that the extended theoretical background she provides in Chapter 9 of her book contains references to many different views in which norms do play a central role, e.g. her discussion of the theory that humans have an innate moral grammar that makes the cognition of norms both possible and pervasive. See Monroe, Ethics, 295-7.

63 At times Monroe acknowledges this point, for example in her interview with the Dutch rescuer Tony and his transformation from a fairly conservative, parochial self-conception to a much more liberal and holistic self-image. See Monroe, Ethics, 66-68; 317-8.

64 Friedlander, Origins of Nazi Genocide, 1-9. 
65 Friedlander, Origins of Nazi Genocide, 17.

66 Eric Weitz, A Century of Genocide: Utopias of Race and Nation (Princeton, NJ: Princeton University Press, 2005).

67 Koonz describes this distinguishing feature as a "concept of ethnic virtue" capable of grounding a "comprehensive ethical revolution." Claudia Koonz, The Nazi Conscience (Cambridge, MA: Harvard University Press, 2005), 13; 16. I do not have space to consider here whether Koonz shares the particular picture of the nature and dynamics of norms that I offer in this paper.

68 Telford Taylor, “Opening Statement of the Prosecution, December 9, 1946,” in George J. Annas and Michael A. Grodin (eds.), The Nazi Doctors and the Nuremberg Code (New York: Oxford University Press, 1992), 88; Evelyne Shuster, "Fifty Years Later: The Significance of the Nuremberg Code," The New England Journal of Medicine 337, 20 (1997): 1436-1440.

69 Paul Weindling, "The Origins of Informed Consent: the International Scientific Commission on Medical War Crimes, and the Nuremberg Code," Bulletin of the History of Medicine 75, 1 (2001): 55, 58.

70 Weindling, “Origins of Informed Consent,” 66-67.

71 See Waller, Becoming Evil, 15-17; Wilson, Writing History.

72 See for example Powell, Barbaric Civilization, 59.

73 The Charter of the International Military Tribunal at Nuremberg famously curtailed one traditional approach to localizing responsibility when it rejected superior orders as a legitimate defense against charges of war crimes or crimes against humanity. While members of military units cannot absolve themselves from legal responsibility for participation in mass atrocities by pointing to superior orders, large-scale crimes such as genocide and mass atrocity are not typically perpetrated solely by soldiers serving in ordinarily constituted military units. The Nuremberg Charter does not, therefore, establish definitively the limits of appropriate localization of responsibility for large-scale crimes. Furthermore, the Nuremberg Charter deals exclusively with legal, rather than moral, responsibility. For both of these reasons, it is appropriate to consider whether there are other forms of localization of legal or moral responsibility that might be justified on the basis of the thesis of norm transformation.

74 Waller, Becoming Evil, 203

75 For a helpful discussion of criteria for assessments of moral responsibility for bystanding behavior during mass atrocities, and of the challenges of incorporating intentions as an element in such assessments, see Ernesto Verdeja, "Moral Bystanders and Mass Violence," in New Directions in Genocide Research, ed. Adam Jones (New York: Routledge, 2012), 153-168.

76 Michael Kearney, The Prohibition of Propaganda for War in International Law (New York: Oxford University Press, 2008).

77 Wilson, Writing History.

78 See Gerlach, "Extremely Violent Societies"; also Gerlach, Extremely Violent Societies: Mass Violence in the Twentieth-Century World (New York, Cambridge University Press, 2010). http://dx.doi.org/10.1017/ CBO9780511781254

79 Gerlach, Extremely Violent Societies, 6.

80 Gerlach, "Extremely Violent Societies," 448-449.

81 Gerlach, Extremely Violent Societies, 284.

82 Gerlach, Extremely Violent Societies, 284.

83 Gerlach, “Extremely Violent Societies,” 453-454.

84 Mark Drumbl, Atrocity, Punishment, and International Law (New York: Cambridge University Press, 2007).

85 Raphael Lemkin, "Introduction to Genocide," in Lemkin on Genocide, ed. Steve Jacobs (Lanham, MD: Lexington Books, 2012), 4. 